\title{
Direct Transplant of Melanocytes from Normal Donor Area into Vitiligenous Recipient Area by Intralesional Injection of Melanocytes Using Spade Like Needle Technique
}

\author{
Khalifa E. Sharquie ${ }^{1,2^{*}}$, Adil A. Noaimi1 ${ }^{1,2}$, Zahraa N. Al-Khafaji ${ }^{3}$ \\ ${ }^{1}$ Department of Dermatology \& Venereology, College of Medicine, University of Baghdad, Baghdad, Iraq \\ ${ }^{2}$ Arab Board for Dermatology \& Venereology, Baghdad Teaching Hospital, Medical City, Baghdad, Iraq \\ ${ }^{3}$ Department of Dermatology \& Venereology, Baghdad Teaching Hospital, Medical City, Baghdad, Iraq \\ Email: "ksharquie@ymail.com, adilnoaimi@yahoo.com, alkhafajizahraa@yahoo.com
}

Received 25 June 2016; accepted 18 September 2016; published 21 September 2016

Copyright (C) 2016 by authors and Scientific Research Publishing Inc.

This work is licensed under the Creative Commons Attribution International License (CC BY).

http://creativecommons.org/licenses/by/4.0/

c) (i) Open Access

\section{Abstract}

Background: Vitiligo is a common autoimmune inflammatory skin disease, where there are different surgical techniques for treatment of stable patches of vitiligo. Objective: To find non-costly, minimally invasive, simple technique by direct melanocytes transplant by spade needle technique in treatment of vitiligo. Patients and Methods: This interventional, therapeutic, comparative study was done in Department of Dermatology, Baghdad Teaching Hospital, Baghdad, Iraq from April 2014-March 2015. Twenty patients with localized, generalized and segmental vitiligo were included. Full history and examination for each patient was done with $4(20 \%)$ males and $16(80 \%)$ females and their ages ranged from $9-40(23.15 \pm 11.44)$ years. Forty one patches in 20 patients treated by spade grafting technique and the donor and recipient sites were demarcated and anesthesia done by xylocaine $2 \%$ with adrenalin 1:100,000. Transplantation was started by using disposable needle gauge 18 (the sharp end of needle was cut by a scissor to make it a spade like) with medical syringe $5 \mathrm{ml}$ supplied with normal saline. The micro-pieces were taken from donor site and transplanted directly, easily and rapidly into dermis of recipient site and followed by pushing normal saline and the procedure was repeated to cover all recipient sites with $5 \mathbf{~ m m}$ distance between injection points. The surface area of the lesions was calculated and the reduction rate was estimated every month till the end of the 4th month period of the treatment. Results: Including 41 patches in 20 patients with the surface area of the patches ranged from $1.5-90 \mathrm{~cm}^{2}(13.78 \pm$ 
17.57) $\mathrm{cm}^{2}$. The mean \pm SD of surface area of lesions was decreased from $13.78 \pm 17.57 \mathrm{~cm}^{2}$ at baseline visit to $13.61 \pm 17.48 \mathrm{~cm}^{2}$ at the second visit (after 2 weeks ) which was statistically significant ( $p$ value $\leq \mathbf{0 . 0 0 1}$ ). The mean surface area continued to be reduced till reaching $12.20 \pm$ $15.68 \mathrm{~cm}^{2}$ at the third visit and $12.01 \pm 15.55 \mathrm{~cm}^{2}$ at the fourth visit. All were statistically significant when compared to baseline visit. There was reduction in surface area $1.1 \%$ at two weeks, $9.93 \%$, and $12.5 \%$ at the $2 \mathrm{nd}, 4$ th months respectively. Conclusions: Intradermal injection of melanocytes in patients with vitiligo by spade like needle was very quick and simple non-costly technique, and gave $12.5 \%$ reduction which could be repeated at different times until satisfactory re-pigmentation of vitiligenous skin is achieved.

\title{
Keywords
}

\author{
Direct Transplant of Melanocytes, Intralesional Injection of Melanocytes, Spade Like Needle, \\ Vitiligo
}

\section{Introduction}

Vitiligo is an autoimmune inflammatory disease that could be very progressive or run a slow course, or some time could be very stable localized area like segmental vitiligo. And in general, there are 2 types of patients with vitiligo in regarding to medical therapy either patients have rapid response to treatment so called rapid responder, while other group with very poor response to treatment so called poor responder [1].

In patients with localized stable patches vitiligo and those with stable but poorly response to treatment like segmental vitiligo, there is the main indication for surgical therapy [2].

These surgical treatment options for vitiligo offer the potential for rapid and more desirable amounts of repigmentation [3]. The different modalities of surgical techniques include: tattooing, organ-cultured fetal skin allografting, epidermal culture grafting, melanocyte culture grafting, autologous noncultured melanocyte-keratinocyte cell transplantation, epidermal grafting by the suction blister technique, thin Thiersch split skin grafting, or miniature punch grafting [4]. And more recently Sharquie et al. invented a new simple technique by direct transplant of melanocytes using micrografting pieces from normal donor area into vitiligenous recipient area with $68 \%$ repigmentation rate in the first 4 months. In this technique, partial splitting skin was harvested and divided into micro-pieces that transplanted directly into vitiligenous skin by using needling puncture [1]. While the aim of this work is to use very easily simple non-costly, minimally invasive technique by dermabrading normal donor area, and then to be injected inside the dermis of vitiligenous skin using spade like needle.

\section{Patient and Methods}

Twenty patients with vitiligo were enrolled in this case interventional, therapeutic, comparative study, 4 males, 16 females and their ages ranged from 9 - 40 years with a mean of $24.45, \mathrm{SD} \pm 10.43$ years. All clinical types of vitiligo including the generalized, localized and segmental were treated. The number of vitiligo patches varied between patients, so the total number of treated patches was 41 (Table 1 ).

\section{Inclusion criteria}

Segmental and localized areas of vitiligo were included. In patient with generalized vitiligo some localized areas were selected and treated either because were cosmetically unacceptable areas or as the patient requested. Activity of the disease was recorded for each patient to fix the duration of stability of the disease (Table 1).

Exclusion criteria

These are including systemic diseases like: diabetes mellitus, hematological diseases like bleeding tendencies, or drug that prevent clotting, and immune compromised patients. All patients stopped their vitiligo treatment at least two months before intervention.

From each patient, formal consent was taken before starting therapy after full explanation about the nature of the disease, course, and the procedure of treatment, follow up, prognosis and the need for pre and post treatment photographs. Also, the ethical approval was performed by the Scientific Committee of the Scientific Council of Dermatology and Venereology-Iraqi Board for Medical Specializations. All patients were photographed by 
Table 1. The types of vitiligo, stability of the disease, and the site of donor areas.

\begin{tabular}{cccccccc}
\hline No. of pt. & Age & Sex & Type of Vitiligo & No. of patches & Stability of the disease in months & Donor Site \\
\hline 1 & 15 & Male & Generalized & 3 & 3 & Thigh \\
2 & 9 & Female & Generalized & 1 & 3 & Thigh \\
3 & 35 & Female & Generalized & 2 & 5 & Thigh \\
4 & 35 & Male & Segmental & 1 & 12 & Arm \\
5 & 26 & Female & Segmental & 3 & 9 & Chest \\
6 & 21 & Female & Generalized & 1 & 6 & Thigh \\
7 & 40 & Female & Generalized & 2 & 12 & Thigh \\
8 & 16 & Male & Segmental & 1 & 2 & Thigh \\
9 & 35 & Female & Localized & 1 & 4 & Back \\
10 & 18 & Female & Generalized & 2 & 3 & Thigh \\
11 & 16 & Female & Generalized & 5 & 7 & Thigh \\
12 & 16 & Female & Generalized & 2 & Unstable & Thigh \\
13 & 8 & Female & Generalized & 1 & 4 & Thigh \\
14 & 35 & Female & Generalized & 4 & 24 & Leg \\
15 & 40 & Female & Generalized & 3 & Unstable & Thigh \\
16 & 21 & Female & Localized & 1 & Gen & Thigh \\
17 & 32 & Female & Generalized & 2 & 36 & Thigh \\
18 & 16 & Female & Segmental & 3 & Unstable & Back \\
19 & 35 & Female & Generalized & 2 & Thigh \\
20 & 20 & Female & Generalized & 1 & & Thigh \\
\hline
\end{tabular}

Samsung Galaxy S4 combines 13 megapixel camera.

\section{Technique of transplant}

When patient lying in semi supine position in good illuminated room. The photo was taken to vitiligenous recipient area and also for donor site. The donor and recipient sites were demarcated and anesthesia by xylocaine $2 \%$ with adrenalin 1:100,000 was given. The idea of putting adrenalin is to stop bleeding during grafting and to make grafting more easily. Dermabrasion of normal donor areas was performed from different hidden in the body by using of ordinary surgical scalpel.

Transplantation was started by using disposable gauge 18 needle; its sharp end was cut by a scissor to make it a spade like (Figure 1) with medical syringe $5 \mathrm{ml}$ supplied with normal saline.

The micro-pieces were taken from donor site by spade needle and transplanted directly, easily and rapidly into the dermis of recipient sites by needle puncture and followed by pushing normal saline and the procedure was repeated to cover all recipient sites with $5 \mathrm{~mm}$ distance between puncture points.

Follow up and evaluation of response in recipient area

Patients were evaluated every 2 weeks for the 1 st month and then monthly for 3 months. Then patients were advised to have natural sunlight exposure every day for at least 15 minutes. After the next 2 weeks assessment of the start of pigment was carried out at the grafting areas. At 2 months the surface area of the new pigmentation was measured and compared with the surface area of the recipient patch before grafting then the rate of pigmentation was calculated by using transparent with square paper, and also to record any side effects.

Follow up and evaluation of donor area

After 2 weeks dressing was removed and then follow up was carried out for 2 weeks for the first month and then monthly for the next 3 months to watch for any Koebner's phenomenon and complications.

\section{Results}

Results included 41 patches in 20 patients with the surface area of the patches ranged between $1.5-90 \mathrm{~cm}^{2}$ with a mean \pm SD of $13.78 \pm 17.57 \mathrm{~cm}^{2}$. 


\section{Mean surface reduction}

The mean \pm SD of surface area of lesions was decreased from $13.78 \pm 17.57 \mathrm{~cm}^{2}$ at baseline visit to $13.61 \pm$ $17.48 \mathrm{~cm}^{2}$ at second visit (after two weeks ) which was statistically significant ( $\mathrm{p}$ value $\leq 0.001$ ). The mean surface area continued to be reduced till reaching $12.20 \pm 15.68$ at third visit and $12.01 \pm 15.55$ at fourth visit. All were statistically significant when compared to baseline visit (Table 2).

\section{Percent Reduction}

There was reduction in surface area $1.1 \%$ at two weeks, $9.93 \%$, and $12.5 \%$ at the $2 \mathrm{nd}$, 4 th months respectively (Figure 2).

\section{Pattern of repigmentation}

The pattern of repigmentation was halo pigmentation in all patients who response.

\section{Side effects}

Donor site Koebner's phenomena was seen in 4 patients from $20(20 \%)$, this was noticed at third visit (two months after grafting), atrophic linear scaring in 2 patients $10 \%$, and post inflammatory hyperpigmentation in 4 patients $(20 \%)$. These side effects were disappeared at fourth months of follow up. while in treated patches there was no side effect during period of follow up.

\section{Discussion}

When medical therapy of vitiligo has failed, surgical treatment is indicated and the main target of surgery is stable localized and segmental vitiligo [5]. The aim of all these procedures is to implant melanocytes from the normal skin into vitiligenous areas [6]. There many surgical procedures but most these methods are time consuming, costly and need sophisticated lab and personnel. Sharquie et al. invented new simple techniques for direct melanocytes transplant. The first one so called direct transplant of melanocytes from normal donor area in to vitiligenous skin by dermabrasion technique which gave $36.78 \%$ repigmentation rate after 6 months of operation [7]. The second technique, direct melanocytes transplant by micrografting needling technique and this gave

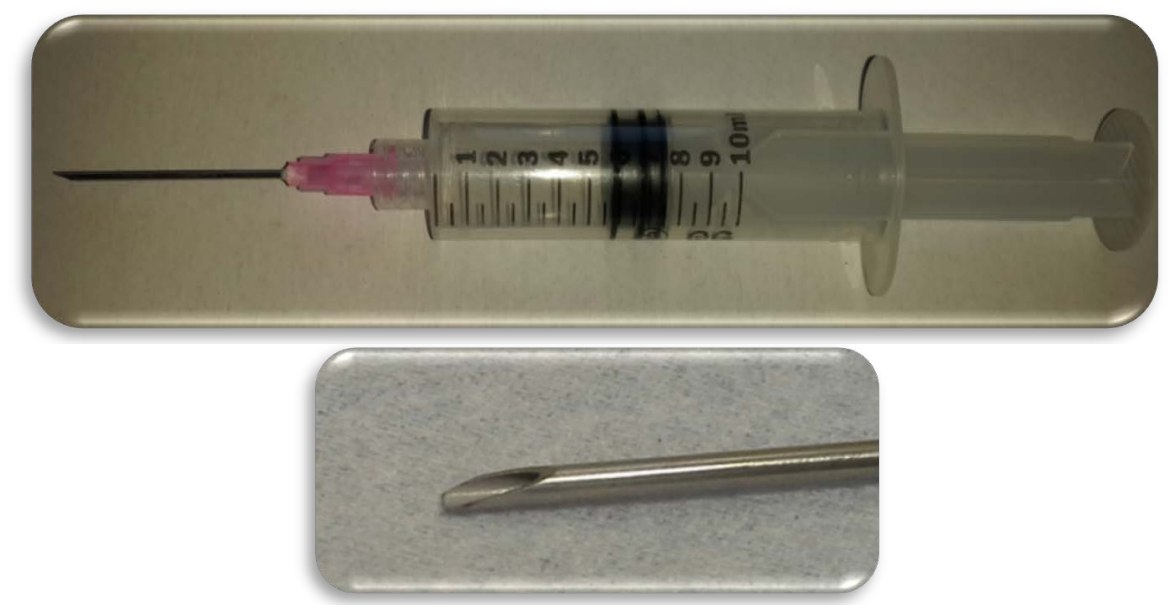

Figure 1. Spade like needle.

Table 2. The mean differences patch size before and after needling using spade like needle.

\begin{tabular}{|c|c|c|c|c|c|}
\hline Variable & Categories & Number of patches & Mean \pm SD & $\mathbf{Z}$ & p value \\
\hline \multirow{2}{*}{ Patch size $\left(\mathrm{cm}^{2}\right)$} & Before needling & 41 & $13.78 \pm 17.57$ & \multirow{2}{*}{-2.226} & \multirow{2}{*}{$<0.001$ ** } \\
\hline & 2 weeks after needling & 41 & $13.61 \pm 17.48$ & & \\
\hline \multirow{2}{*}{ Patch size $\left(\mathrm{cm}^{2}\right)$} & Before needling & 41 & $13.78 \pm 17.57$ & \multirow{2}{*}{-4.034} & \multirow{2}{*}{$<0.001$ ** } \\
\hline & 2 months after needling & 41 & $12.20 \pm 15.68$ & & \\
\hline \multirow{2}{*}{ Patch size $\left(\mathrm{cm}^{2}\right)$} & Before needling & 41 & $13.78 \pm 17.57$ & \multirow{2}{*}{-4.03} & \multirow{2}{*}{$<0.001$ ** } \\
\hline & 4 months after needling & 41 & $12.01 \pm 15.55$ & & \\
\hline
\end{tabular}

"p value $\leq 0.05$ was significant; ${ }^{* *}$ p value $\leq 0.05$ was significant; Wilcoxon Signed Ranks Test. 

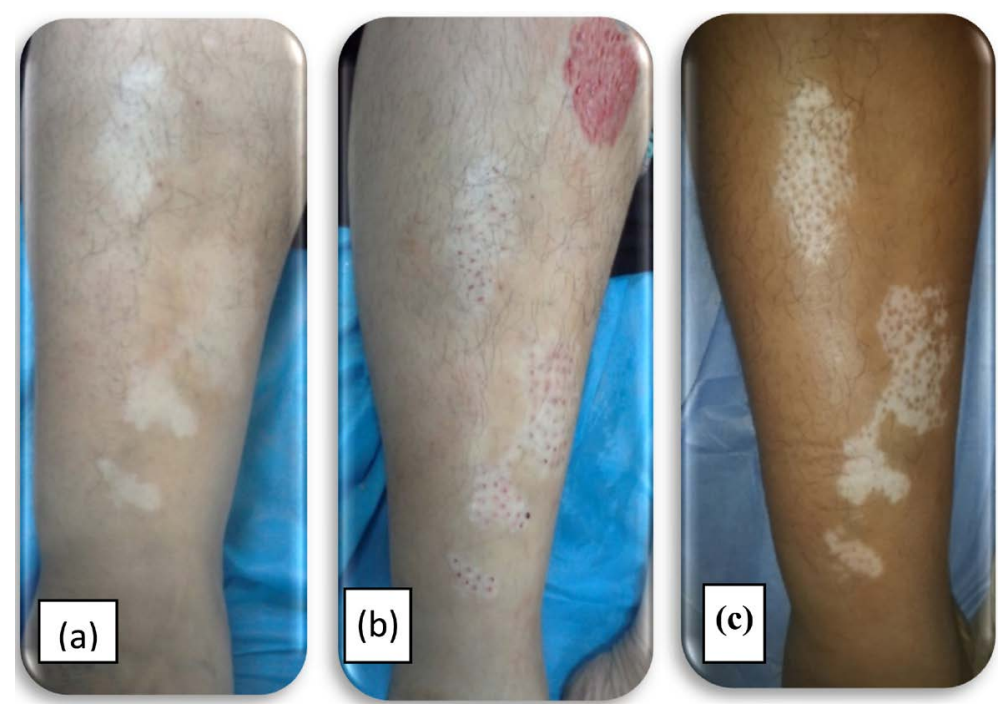

Figure 2. Showing 35 years old female with generalized vitiligo treated by spade micro grafting technique. (a), (b) at the 1 st visit and (c) at 4 months.

$61.36 \%$ repigmentation rate at four months. These two techniques were quick and non-costly and gave a very high success rate within short time, when compared with cultured and non-cultured melanocytes transplant techniques [8]-[11].

The aim of present work is to find much quicker, simple and the least costly than others techniques, by taking debradated normal donor skin using a spade like needle to be injected into dermis of the vitiligenous site.

The results of present work showed that the repigmentation rate was $12.5 \%$ at 4 months. And this rate of pigmentation is high within short time but much lower than previous Sharquie et al. techniques. Accordingly because this technique very easy simple, it could be repeated every month until will full repigmentation of vitiligenous skin was reached.

\section{Conclusion}

Intralesional injection of melanocytes by spade like needle was very quick and simple technique, and gave $12.5 \%$ reduction rate which could be repeated every month until achieving satisfactory repigmentation of vitiligenous skin.

\section{Disclosure}

This study was an independent study and not funded by any drug companies.

\section{References}

[1] Sharquie, K.E., Noaimi, A.A. and Al-Mudaris, H.A. (2013) Melanocytes Transplantation in Patients with Vitiligo Using Needling Micrografting Technique. Journal of Drugs in Dermatology, 12, e74-e78.

[2] Halder, R.M. and Young, C.M. (2000) New and Emerging Therapies for Vitiligo. Dermatologic Clinics, 18, 79-89. http://dx.doi.org/10.1016/S0733-8635(05)70149-2

[3] Mahmoud, B.H., Hexsel, C.L. and Hamzavi, I.H. (2008) An Update on New and Emerging Options for the Treatment of Vitiligo. Skin Therapy Letter, 13, 1-6.

[4] Savant, S.S. (2005) Surgical Therapy of Vitiligo: Current Status. Indian Journal of Dermatology, Venereology, and Leprology, 71, 307. http://dx.doi.org/10.4103/0378-6323.16778

[5] Falabella, R. and Barona, M.I. (2009) Update on Skin Repigmentation Therapies in Vitiligo. Pigment Cell \& Melanoma Research, 22, 42-65. http://dx.doi.org/10.1111/j.1755-148X.2008.00528.x

[6] Rusfianti, M. and Wirohadidjodjo, Y.W. (2006) Dermatosurgical Techniques for Repigmentation of Vitiligo. International Journal of Dermatology, 45, 411-417. http://dx.doi.org/10.1111/j.1365-4632.2006.02486.x 
[7] Sharquie, K.E., Noaimi, A.A. and Al-Mudaris, H.A. (2013) Direct Melanocytes Transplant from Normal Donor Area into Vitiliginous Recipient Area by Dermabrasion Technique. Journal of Drugs in Dermatology, 12, 74-78.

[8] Mulekar, S.V. (2003) Melanocyte-Keratinocyte Cell Transplantation for Stable Vitiligo. International Journal of Dermatology, 42, 132-136.

[9] Olsson, M.J. and Juhlin, L. (1998) Leucoderma Treated by Transplantation of a Basal Cell Layer Enriched Suspension. British Journal of Dermatology, 138, 644-648.

[10] Czajkowski, R., Placek, W., Drewa, T., Kowaliszyn, B., Sir, J. and Weiss, W. (2007) Autologous Cultured Melanocytes in Vitiligo Treatment. Dermatologic Surgery, 33, 1027-1036.

[11] Lotti, T., Gori, A., Zanieri, F., Colucci, R. and Moretti, S. (2008) Vitiligo: New and Emerging Treatments. Dermatologic Therapy, 21, 110-117. http://dx.doi.org/10.1111/j.1529-8019.2008.00178.x

\section{Submit or recommend next manuscript to SCIRP and we will provide best service for you:}

Accepting pre-submission inquiries through Email, Facebook, LinkedIn, Twitter, etc.

A wide selection of journals (inclusive of 9 subjects, more than 200 journals)

Providing 24-hour high-quality service

User-friendly online submission system

Fair and swift peer-review system

Efficient typesetting and proofreading procedure

Display of the result of downloads and visits, as well as the number of cited articles

Maximum dissemination of your research work

Submit your manuscript at: http://papersubmission.scirp.org/

Or contact jcdsa@scirp.org 